\title{
O pioneirismo de Louis Le Guillant na reforma psiquiátrica e psicoterapia institucional na França: a importância do trabalho dos pacientes para a abertura dos hospícios
}

\section{The pioneering spirit of Louis Le Guillant on Psychiatric Reform and Institutional Psychotherapy in France: the importance of the work of patients for the opening of the hospices}

\section{Paulo César Zambroni-de-Souza*}

Docente do Mestrado em Psicologia Social da Universidade Federal da Paraíba UFPB, J oão Pessoa, PB, Brasil

\section{Milton Athayde**}

Docente do Programa de Pós-Graduação em Psicologia Social da Universidade do Estado do Rio de Janeiro - UERJ, Rio de Janeiro, RJ, Brasil

\section{Anísio J osé da Silva Araújo***}

Docente do Mestrado em Psicologia Social da Universidade Federal da Paraíba UFPB, J oão Pessoa, PB, Brasil

\section{Ana Maria Ramos Zambroni de Souza****}

Mestranda em Saúde Pública na Escola Nacional de Saúde Pública Sérgio Arouca ENSP / FIOCRUZ, Rio de J aneiro, RJ, Brasil

\begin{abstract}
RESUMO
O artigo apresenta elementos da vida e da obra do psiquiatra francês Louis Le Guillant relativos às suas contribuições no campo da nascente Psicoterapia Institucional / Reforma Psiquiátrica na França, em particular nas décadas de 1940 e 1950. O método baseou-se em busca exaustiva da produção escrita de Le Guillant, de seus críticos, de psiquiatras próximos a ele e da geração seguinte, analisando cada um dos textos referidos, cruzando as informações entre si e, sempre que necessário, com a história da França e internacional no século XX. Demonstra que ele exerceu uma prática e levantou questões teóricas que podem ajudar a compreender problemas que se enfrentam hoje na Reforma Psiquiátrica brasileira, no que diz respeito a temas como saúde, trabalho, moradia, organização, entre outros. Deste modo, este artigo busca colaborar para conhecer parte da riqueza da obra deste autor, insuficientemente conhecido.
\end{abstract}

Palavras-chave: atenção psicossocial; reforma psiquiátrica; psicoterapia institucional; psiquiatria social; trabalho. 


\begin{abstract}
This article presents elements of life and work of French psychiatrist Louis Le Guillant for their contributions in the field of young institutional psychotherapy / Psychiatric Reform in France, particularly in the 1940s and 1950s. The method was based on exhaustive search of the written production of Le Guillant, its critics, of psychiatrists coming to him and the next generation, examining each of these texts, crossing the information among themselves and, where necessary, with the history of the France and the international in the twentieth century. Shows that he had a practical and theoretical issues raised that can help understand on problems that are facing today in the Brazilian Psychiatric Reform, regarding issues such as health, work, housing, organization, among others. Thus, this paper works to know that wealth of works by this author are insufficiently known.
\end{abstract}

Key-words: Psychosocial care; psychiatric reform; institutional psychotherapy; social psychiatry; work.

\title{
I ntrodução
}

O psiquiatra francês Louis Le Guillant (1900-1968) é consensualmente considerado na França (LOURAU, 1975; DEJ OURS, 1980; LEVY-LEBOYER, 1987; BILLIARD, 1996; CLOT, 1996; DORAY, 1996; LIMA, 1998; LIMA, 2002) um dos principais líderes de um grupo de precursores/fundadores da Psicoterapia Institucional e da Reforma Psiquiátrica francesa, fundador, com Paul Sivadon, da Psicopatologia do Trabalho (ZAMBRONI-DE-SOUZA E ATHAYDE, 2006). Apresenta um pensamento original sobre a atenção em saúde mental e sobre as relações subjetivas dos seres humanos no seu meio de vida e trabalho.

Este artigo mostra que além desse feito - que já seria motivo para Le Guillant ser muito mais conhecido no Brasil - ele colocou questões em seu tempo, na esfera do que chamamos hoje de Reforma Psiquiátrica, fazendo experiências e pesquisas, apontando para problemas e para encaminhamentos ainda sem solução. Assim, ao revisitar as fontes da Reforma Psiquiátrica e da Psicoterapia Institucional na França vai-se ao encontro da vida e da obra deste personagem, o que pode lançar luz sobre tais problemas.

Mesmo na França, no entanto, sua obra não se tornou conhecida à altura de sua importância. Até 1984 seus textos encontravam-se dispersos, só então foi publicada uma coletânea de 25 de seus textos, no livro intitulado Quelle Psychiatrie pour notre temps? Travaux et écrits de Louis Le Guillant (Que Psiquiatria para nosso tempo? Trabalhos e escritos de Louis Le Guillant), organizado pelo coletivo denominado "Grupo de Trabalho Louis Le Guillant". Prefaciado por seu companheiro de trajetória, Lucien Bonnafé, é uma obra extensa, com 450 páginas. Em 2006 foi publicado, na França, o livro intitulado Le drame humain du travail ( $O$ drama humano do trabalho), com seis textos selecionados do autor (já contidos no livro de 1984), sobre o que hoje vem sendo denominada por "clínica do trabalho" (LHUILIER, 
2006). O autor mais destacado da abordagem Clínica da Atividade, Yves Clot, faz a apresentação dos dois últimos livros citados. No Brasil foi publicado, também em 2006, o livro Escritos de Louis Le Guillant: da ergoterapia à psicopatologia do trabalho, com onze textos do autor.

No campo mais amplo da luta pela Saúde Mental e Reforma Psiquiátrica, a Psicoterapia Institucional e suas derivações - como a Sociopsicanálise, Análise Institucional e a Esquizoanálise - já faziam referências a Le Guillant, dado seu papel fundador, também aí, como figura destacada da corrente francesa chamada "revolução psiquiátrica". No Brasil, em 1975 foi publicado o livro de René Lourau, Análise Institucional (saído na França em 1970), em que o autor apresenta Le Guillant como um dos fundadores do movimento de Psicoterapia Institucional. Registra, citando-o, que nosso personagem acentuara outrora a

[...] revolta, nascida em um contexto social e político determinado [...] da tomada de consciência que suscitou em nós com relação à opressão de nossos doentes, que nós mesmos acabávamos de viver, às condições desumanas que eram muitas vezes as deles e que foram, durante estes anos, levadas a um grau de evidência intolerável (LE GUILLANT, apud LOURAU, 1975, p. 181).

Lourau, no mesmo livro, dando continuidade a este raciocínio, fazendo alusão à 2a ${ }^{a}$ Guerra (ou seja, no caso da França, à ampla aceitação inicial do nazismo, seguida da ocupação militar, em paralelo à resistência popular vitoriosa ao nazismo), lembra Le Guillant em sua afirmação: “Nossa primeira 'revolução' continha essencialmente esta nova atitude com relação aos doentes, a saber, o respeito, a solicitude, o interesse, o reconhecimento deles enquanto pessoas" (idem).

Ressalta-se que não é intenção deste artigo tratar da importância de Le Guillant para as investigações sobre a relação saúde mental / trabalho, de modo que se remete o leitor para uma aproximação a este tema, aos textos do próprio autor, assim como a Zambroni-deSouza ; Athayde (2006), entre outros.

\section{Método}

Para a construção deste artigo procurou-se um contato exaustivo com a produção escrita de Le Guillant. A obra mais completa é a coletânea de textos escolhidos (Quelle Psychiatrie pour notre temps? Travaux et écrits de Louis Le Guillant), mas o livro publicado em 2006 na França (Le drame humain du travail: essais de psychopathologie du travail), contém de original uma importante apresentação de Yves Clot. Utilizamos também o livro publicado no Brasil em 2006 (Escritos 
de Louis Le Guillant: da ergoterapia à psicopatologia do trabalho), pois contém a apresentação de Lima, o pósfácio de Codo e permite o conhecimento dos textos do autor pelo público brasileiro, sendo, por este motivo, a fonte principal das citações deste artigo. Quando necessário fez-se a busca de outros de seus escritos em revistas francesas (por exemplo, L'Évolution Psychiatrique, Information Psychiatrique e La Raison). Utilizou-se também obras de seus parceiros mais próximos, sejam psiquiatras de sua geração, como Paul Sivadon, ou de contemporâneos da geração seguinte, como Lucien Bonnafé (com quem criara a revista La Raison, incentivados por Henri Wallon). Foram também agregados para a análise tanto materiais de seus contemporâneos de debates (como foi o caso de F. Tosquelles, líder da clássica experiência de Saint Alban e da constituição da Psicoterapia Institucional, em ambos os casos na companhia de Bonnaffé), quanto seus comentadores e críticos, assim como aqueles que buscam hoje explorar suas potencialidades, entre os quais Doray e Clot. Entre os autores brasileiros encontrou-se um reduzido número de referências, sendo a primeira em SeligmannSilva (1986), depois em Codo, Sampaio ; Hitomi (1993) e em Athayde (1996), em seguida Lima (1998; 2002; 2003; 2006); Merlo (2002), Jacques (2003), Nassif (2005), Codo (2006), Zambroni-deSouza ; Athayde (2006) e Zambroni-de-Souza (2006).

Colocou-se em análise cada um dos textos referidos, cruzando as informações entre si e, sempre que necessário, com a história da França e do século XX (HOBSBAWM, 1995). Assim, procurou-se compreender suas experiências e proposições teórico-metodológicas e práticas, o impacto de suas idéias, situando-as historicamente, assim como sua história de vida, seu estilo de pensamento e suas filiações filosóficas e políticas.

\section{Experimentações durante e Pós-2a Guerra Mundial}

Le Guillant foi diretor do hospital psiquiátrico de Charité-sur-Loire (na região de Nièvre) de 1932 a 1944, onde, como outros psiquiatras o fizeram (como Tosquelles em Saint Alban), também acolheu diversos maquisards, membros clandestinos da Resistência, em seguida outros refratários ao sistema instituído.

Naquele hospital, em 1940, frente ao iminente risco de bombardeio pelos nazistas (ou de seu aprisionamento e encaminhamento para "limpeza" eugênica) ocorreu que:

Tendo obtido a aprovação do administrador do departamento, a nossa colega Dra. Petit tomou a excelente iniciativa de libertar um certo número de pacientes - 38 homens e 65 mulheres, calmos, lúcidos, cujas família se encontravam na região, providos de alguns víveres (LE GUI LLANT, 2006a, p. 78). 
Os que não foram formalmente liberados, aterrorizados com a possibilidade dos bombardeios, decidiram fugir e abandonaram o hospital (contando com a assumida conivência do diretor). O que daí resultou foi surpreendente: terminada a Guerra, constatou-se que grande parte deles conseguira ótima adaptação, seja ficando bem no convívio com suas famílias, seja trabalhando em fazendas da região em troca de comida e abrigo. Com base neste confronto com a relidade concreta constatada, Le Guillant chegou à conclusão de que eles não precisavam necessariamente ficar internados e que melhor seria para a maior parte deles a vida real, fora dos hospícios. É o que ele defende em "Uma experiência de readaptação social instituída pelos acontecimentos da guerra" (LE GUILLANT, 2006a, 2006b), conferência corajosamente apresentada à Sociedade MédicoPsicológica em 1941. Esta descoberta, realizada na crua empiria da barbárie da guerra, deu o norte de sua caminhada teórico-prática, a partir de então.

Toca-se aqui em dois pontos hoje fundamentais para os rumos da Reforma Psiquiátrica brasileira: moradia e trabalho (e a moradia já mobiliza uma forma de trabalho nobre e incontornável, como o doméstico, não obstante sua desqualificação social) para usuários dos serviços de Saúde Mental. Sabe-se que o advento do alienismo por Pinel coincidiu com a criação do Hospício, o que fez com que muitas pessoas fossem internadas em estabelecimentos manicomiais e tivessem suas identidades tão marcadas pelas instituições que aí circulam, passando a ter muitas dificuldades de viver fora do espaço fechado (GOFFMAN, 2001). No caso da experiência de Le Guillant e os pacientes de Charité-sur-Loire, a violência da guerra paradoxalmente proporcionou a saída das condições da outra violência - a do manicômio - , exigindo novos devires.

Na recente conjuntura brasileira, em função dos avanços da Reforma Psiquiátrica, houve uma significativa redução de leitos em manicômios, reconhecendo que muitas vezes são objeto de violência, cronificação e corrupção, malgrado a luta de tantos psiquiatras e demais profissionais de saúde comprometidos com a vida. Como nestes estabelecimentos havia um grande número de pessoas já sem contato com suas famílias ou que, por circunstâncias diversas, não teriam condições de mantê-las, em tantos outros casos não seria positivo para sua recuperação (LE GUILLANT, BONAFFÉ, MIGNOT, 2006) voltar a morar com ela, colocou-se a questão de como fazer para que estas pessoas pudessem viver fora do hospício. Para dar conta dessa problemática, têm sido criadas "Residências Terapêuticas" para que possam ter onde morar (BRASIL, Portaria $\mathrm{n}^{\circ}$ 106/MS, de 11/02/2000). Nestas residências emerge a incontornável necessidade de realizar os cuidados com o dia a dia da vida, da casa, de cuidar de si próprio, de negociar as relações com os outros, de 
modo que se chama aqui atenção para a presença da atividade de trabalho doméstico sendo aí experimentado.

Quando se fala do trabalho doméstico, trata-se de investigações ainda recentes, fruto das conquistas do movimento feminista, explorado no campo científico, sobretudo pela Sociologia das relações sociais de sexo, com autoras como Danièle Kergoat, Helena Hirata, J oan Scott, entre outras. A investigação do trabalho doméstico traz a exigência de inovações teórico-metodológicas, algo a ser ainda melhor explorado pela Psicologia.

Le Guillant viu no evento da liberação forçada dos pacientes em Charité-sur-Loire a possibilidade de pensar o lugar do trabalho na vida das pessoas até então internadas diferentemente do que propunha a Psiquiatria clássica e até mesmo a Ergoterapia, que foi um marco fundamental em grande parte das tentativas de reforma na França. Cabe lembrar que as tentativas de transformação da Psiquiatria ocorridas no século $X X$ designaram um importante lugar para o trabalho dos pacientes-usuários. Marca-se o grande alcance que a obra de Hermann Simon - difundida, sobretudo, através do livro de 1929, Por uma terapêutica mais ativa no hospital psiquiátrico - alcançou, de modo que a Ergoterapia por ele proposta teve grande influência nas reformas psiquiátricas, em especial na França, no movimento da psicoterapia institucional, como será tratado neste artigo.

A criação do hospício por Pinel teve como uma de suas justificativas teóricas a suposta incapacidade de trabalhar dessas pessoas, o que confirmava a necessidade de sua reclusão para tratamento, conforme mostra Foucault (1987, p. 78): “[...] o momento em que a loucura é percebida no horizonte social da pobreza, da incapacidade para o trabalho, da impossibilidade de integrar-se no grupo [...]".

o julgamento de "incapacidade de trabalhar" tende a participar o tempo todo no trabalho destas pessoas, mas é exatamente na atividade que se criam condições de ampliar os limites pessoais de cada ser humano, como parece ter ocorrido com os ex-internos de Charité-sur-Loire. Le Guillant, neste sentido, contribuiu para a compreensão de que o trabalho pode ser lugar de desenvolvimento de todas as pessoas, inclusive daquelas com percursos pela rede de cuidados (muitas vezes maus tratos) de Psiquiatria e Saúde Mental.

$\mathrm{Na}$ medida em que enfrentam e superam aquele julgamento social que supõe sua incapacidade e buscam recursos pessoais para dar conta de realizar a atividade, desenvolvem potencialidades que muitas vezes nem elas mesmas sabiam possuir (ZAMBRONI-DESOUZA, 2006). Esta maneira de abordar o trabalho encontra hoje desenvolvimentos em autores franceses como Christophe Dejours, Yves Schwartz, Yves Clot, François Daniellou e outros. Uma maior visibilidade do trabalho de um grupo que tradicionalmente foi considerado incapaz de trabalhar torna possível pensar em formas 
diferentes de organizar o trabalho das que têm sido hegemônicas, criadoras de competição e danos para a vida e saúde de todos que trabalham em meio a esta lógica.

Defende-se aqui que o trabalhar de "psiquiatrizados" pode trazer ganhos não só para aquelas pessoas, mas também para a sociedade como um todo, já que tais experimentações, conduzidas muitas vezes silenciosamente na vida dessas pessoas, que frequentemente têm que esconder do empregador e dos colegas de trabalho sua história de tratamento para problemas mentais, pode ser fonte de "reservas de alternativas". Schwartz (2000, p. 703), ao falar da imprevisibilidade das futuras transformações do espaço social frente ao trabalho, diz que a atividade é sempre fonte daquelas reservas, ou seja, que a atividade, o ser humano em movimento, pode dar origem a diversas realidades, de modo que na atividade se abrem caminhos que possibilitam transformação do modo das pessoas viverem e trabalharem. $O$ fato daqueles ex-internos terem sobrevivido às penúrias da guerra, valendo-se para isto de seu trabalho na região em que sobreviveram, abriu caminho para pensar outras formas de relação com elas, contribuindo para os primeiros passos da Reforma Psiquiátrica na França.

É importante lembrar que se trata da década de 1940, quando começavam a surgir os primeiros movimentos do que em 1952 foi denominado por Daumezon "Psicoterapia Institucional", considerada por alguns de seus expoentes como uma tentativa de melhorar, de reformar o hospital psiquiátrico, e não de prescindir dele (CASTEL, 1978, p.53). Esta posição remete a um debate sobre o qual existem controvérsias. No interior deste movimento, muitos consideravam o hospital psiquiátrico como um dispositivo necessário, mas apenas para preparar o doente para viver fora dele e não para que ele, cronificado, seguindo uma carreira instituída, passasse ali o resto de sua vida, como frequentemente ocorria, seja de maneira contínua, seja através do revolving door, os constantes retornos ao manicômio. Tosquelles, por exemplo, chega a afirmar que o período de internação no hospital deve servir de "escola de liberdade" (entrevista a GALLIO; CONSTANTINO, 1994, p. 93). Le Guillant falava da necessidade de "transformar profundamente o espírito dos hospitais psiquiátricos" (2006a, p. 91), apesar de alertar para o fato de que a "privação de liberdade é um ato grave e positivo, cuja necessidade deve, incessantemente, ser questionada" (p. 92), acrescentando que "a criação de uma assistência extra-hospitalar será capaz de multiplicar estas reintegrações sociais" (p. 92-93).

Ainda para realçar a relevância destas experiências e deste debate, lembra-se que a Reforma Psiquiátrica segue rumos distintos em cada país (DESVIAT, 1999) e que estas ações de Le Guillant ocorreram muito antes do movimento da Psiquiatria Democrática italiana, já que os trabalhos de Franco Basaglia em Gorizia e Trieste ocorreram na 
década de 1960 e 1970 (BASAGLIA, 2005a; 2005b; BARROS, 1994; AMARANTE, 1994).

A Psicoterapia Institucional na França insere-se em um movimento que já nos anos 30 buscava reformas (também na Espanha, com as experimentações de Tosquelles na Guerra Civil, antes de fugir para a França). Frente às graves dificuldades econômicas e à ameaça nazifascista no exterior, de 1934 até 1936 as forças de esquerda organizaram-se em torno do que se denominou "Frente Popular", levando ao poder de Estado uma coalisão (envolvendo os partidos autodenominados comunista, socialista e radical) vitoriosa nas eleições de maio de 1936. Apesar de desagregar-se a partir de 1937, neste curto período um programa de governo levou a diversos decretos muito importantes no âmbito do trabalho e da saúde.

Voltando à violência da $2^{a}$ Guerra, Le Guillant não deixou de tirar conseqüências destes acontecimentos. Esta conjuntura criou a urgência de encontrar mão de obra que pudesse substituir os que deixaram a produção para ir ao combate na Resistência, assim como aqueles que sofreram lesões. Assim, foi necessário tentar adaptar ao trabalho produtivo mulheres, idosos e os chamados doentes mentais, como na Inglaterra, onde um quadro semelhante levou à criação da chamada Abordagem Sociotécnica, tendo como centro o Instituto Tavistock de Londres (ORSTMAN, 1984).

Ao lado de outros tipos de esforços e investigações que permitiram a inserção no trabalho daquelas pessoas até então consideradas incapazes de trabalhar encontra-se a Ergoterapia. Esta abordagem, que já havia antes sido inventada na Alemanha por Hermann Simon na década de 1920, pois ele verificara em suas viagens de trabalho que nos hospitais em que os internados tinham, de algum modo, atividade de trabalho, eles se apresentavam em melhores condições, o que o levou a propor o trabalho aos pacientes-usuários como forma de terapia e passou a ser freqüentemente utilizada também em hospitais franceses (VERTZMAN; CAVALCANTI; SERPA JÚNIOR, 1992, p.20). Ela fez parte do patrimônio mobilizado por Tosquelles no Hospital Saint Alban, em Lozère. A Psicanálise também exerceu forte influência em alguns daqueles hospitais (DESVIAT, 1999, p.25). Le Guillant, no entanto, critica a Ergoterapia, tal como praticada em diversos hospitais, denunciando o uso não remunerado do trabalho que os pacientes ali realizavam (LE GUI LLANT, 2006a; LE GUI LLANT, ACHAINTRE, JACQUELIN, 2006). A partir de um dado momento, com o próprio Bonnafé (que fora antes o diretor de Saint Alban), passaram a fazer críticas ao caminho que tomava a experimentação dirigida por Tosquelles, dado que mais pareceria um modelo ideologizado de hospital-falanstério, o que poderia levar os internados a não querer enfrentar as contradições, presentes na sociedade e que caracterizam a vida (HESS ; SAVOYE, 1993). Em um dado período, no pós-guerra, chegou mesmo a recusar a Psicanálise, 
seguindo uma ordem internacional recebida pelo Partido Comunista Francês.

\section{Aproximação com o marxismo e o Partido Comunista Francês}

Seu espectro de atenção como psiquiatra envolvia ainda, desde antes da guerra, outros problemas sociais e esforços de mudança. Fruto de sua permanente ligação com o mundo infantil - já em 1929 fora chefe de clínica de Neuropsiquiatria Infantil, na Clínica de N.P.I. aux Enfants Malades, com o Dr. Heuyer - em 1944 (até 1947) foi nomeado como conselheiro técnico sobre assuntos relativos à "criança deficiente e em perigo moral" (CENTRE HOSPITALIER CHARCOT, 2008), junto a François Billoux, ministro da saúde pública e membro do Partido Comunista Francês. Outros psiquiatras ilustres, como Bonnafé, também foram conselheiros no Ministério da Saúde, então sob direção do PCF. Em 1943 Le Guillant tornou-se membro do "Conselho técnico da criança deficiente e em perigo moral" (também dirigido pelo Dr. Heyer), em seguida foi nomeado para escalão superior. Suas relações profissionais com a infância e com pesquisadores deste campo (como Henry Wallon, sendo do comitê de redação da revista Enfance, fundada por Wallon) continuou até o fim de sua vida profissional: em 1946 fundou a revista Sauvegarde, das Associations Régionales de Sauvegarde de l'Enfance et de l'Adolescence e é membro de seu comitê diretor até 1950.

Não faz parte do escopo deste artigo entrar nas proposições de Le Guillant sobre a infância, tema que será tratado em outro artigo, apenas assinala-se aqui sua importância para a atenção à saúde mental da criança, marcando que a proximidade com o então ministro Billoux (indicado pelo PCF), aliado ao seu interesse por Marx e o materialismo histórico, fecundado no período da luta da Resistência (anti-fascista), levaram-no a filiar-se ao Partido Comunista Francês em 1947, quando o partido saiu do governo. Diversos outros psiquiatras já haviam feito seu engajamento no Partido quando Le Guillant o fez. Lebovici, por exemplo, em 1945.

\section{A terapêutica pelo trabalho e a política de setor}

Em 1947, Le Guillant assumiu a posição de médico chefe no hospital de Villejuif, em Paris, onde ficou até 1965. Ali fundou em 1949 o Centro de Tratamento e Readaptação Social, o segundo da França, visto o primeiro ter sido fundado por Sivadon em 1947 em VilleEvrard (BILLIARD, 2001). Aproveitando-se da proximidade de contatos com a Sécurité Sociale, ele funda este Centro, conseguindo constituir uma importante equipe, no qual se multiplicaram "clubes" (expressão francesa dada a este tipo de dispositivo associativo) efêmeros ou permanentes, associados a um "clube de pós-cura" denominado l'Elan - todos sob o resguardo de associação “l'Elan retrouvé". Conforme a perspectiva de Sivadon, esta estruturação 
permitia conduzir a terapêutica pelo trabalho e o que denominavam a "reinserção social dos doentes". No imediato pós-guerra, um grupo destacado de psiquiatras, Ey, Sivadon e Le Guillant - no processo de mudanças no qual militava ${ }^{1}$ todo um grupo - põe em cena um outro tipo de dispositivo-serviço que denominam Centro de Tratamento e Readaptação Social (CTRS). Neste serviço, os deveres relativos à hospitalização tornar-se-iam literalmente secundários, posto que para eles o campo primordial ou principal de responsabilidade era o mundo exterior. Consideravam aberrante tanto reduzir a relação terapêutica ao tempo e ao lugar da hospitalização, quanto tratar o transtorno mental como se ele se passasse simplesmente no "envelope corporal do sujeito".

É preciso compreender a existência de condições históricas de diversas ordens para que trajetórias como as de Le Guillant pudessem emergir e se desenvolver. E que as condições necessárias para as significativas mudanças no cuidado com a saúde mental exigiriam uma verdadeira subversão do aparelho de cuidados existente, de modo que o acolhimento, a "ressocialização" e o tratamento fossem realizados o mais próximo possível do lugar de vida daqueles considerados doentes mentais.

Em torno destas questões foram realizadas "Jornadas Nacionais" em 1945 e 1947, quando se esboçaram os possíveis destas mudanças, posteriormente configurando-se no que foi chamado "política de setor". Foram criadas no combate conduzido pelo sindicato dos médicos dos hospitais psiquiátricos (de grande importância em todo este processo), pautado na modernização do hospital, na multiplicação dos dispensários, na criação de estruturas extrahospitalares e no aumento dos efetivos de pessoal médico e "paramédico". Le Guillant defendia que os médicos deveriam ter participação na assistência não-asilar. Para os que não pudessem sair do asilo, deveriam trabalhar tanto pela criação de mecanismos não previstos pelas antigas leis francesas (Lei de $1838^{2}$ ), quanto pela fusão do asilo com serviços abertos, sempre buscando condições técnicas favoráveis nos novos serviços (LE GUILLANT, PARIENTE, ROELENS, TORRUBIA, 2006).

Uma figura de destaque nesta produção coletiva foi Georges Daumézon, secretário-geral daquele sindicato, fundado em 1945 a partir da dissolução do organismo anteriormente existente. Sua primeira direção estava mobilizada pela condenação da conduta segregativa da sociedade, exigindo subverter o hospital - lugar visto como concentracionário, conforme a lógica asilar, cuja nocividade tornou-se mais visível dada a ocupação nazista da França transformando-o em instrumento de cuidados, deslocando a responsabilidade do paciente para a sociedade. Tal aparelho de cuidados exigiria neutralizar os efeitos patogênicos das estruturas hierárquicas, horizontalizando-as, viabilizando encontros em que a 
palavra estaria podendo circular, momento em que a dimensão do humor pode emergir como elemento terapêutico.

\section{A equipe de cuidados a a formação de enfermeiros}

Ainda em 1949, Le Guillant foi responsável, com Daumézon, pelo primeiro estágio para enfermeiras/os de hospitais psiquiátricos no Centro de Treinamento nos Métodos de Educação Ativa (CEMEA), organismo no qual atuou de 1945 até sua aposentadoria, em 1968. Registra-se aqui a presença destacada de Germaine Le Henaf, com quem Le Guillant se casou em 1953. Ela era apaixonada pela educação infantil. Durante a 2a Guerra dirigira uma "maison d'enfant" (casa de criança) - La Guette. Aí acolheu crianças judias, por toda sua coragem recebendo em 1986 a "medalha dos justos". Em seguida se deu o encontro com o CEMEA. Após a guerra, ela passa a militar como cemeista, inicialmente na formação de monitores de colônias de férias, sendo em seguida convidada por Daumézon para organizar estágios para enfermeiras em Psiquiatria.

Através destes estágios começaram a perturbar as práticas tradicionais das enfermeiras, assim como sua percepção da doença mental. Tais estágios, por toda a França, permitiam às enfermeiras, até então isoladas em seus locais de trabalho, poder falar mais livremente de suas relações com os pacientes, os colegas e psiquiatras. Na França, diferentemente do Brasil, até recentemente a formação de enfermeiras psiquiátricas e enfermeiras generalistas se dava em escolas distintas, de modo que a qualificação destas profissionais e a democratização destas relações puderam também manifestar-se nos cuidados por elas prestados.

Relembrando a necessidade de compreender as condições históricas para analisar uma situação pregressa e a dialética ali presente, notase que em Le Guillant não havia a crítica à centralidade do médico, como figura primordial na assistência aos pacientes (LE GUILLANT, PARIENTE, ROELENS, TORRUBIA, 2006; DALLE, DUBOIS, LE GUILLANT, HORASSIUS, RETANA, COX, LEFRANC, 2006) e a tutela que daí advém (BASAGLIA, 2005a). Ainda assim, estes estágios iniciaram uma reviravolta nos hospitais psiquiátricos, abrindo-os para o exterior. Em 1954, junto com Daumézon, Le Guillant fundou a revista Vie Sociale et Traitement, 'dando a palavra' às enfermeiras e Ihes permitindo partilhar suas experiências. A partir de então se começa a falar de um coletivo, uma equipe de cuidados.

\section{- Simpósio sobre a Psicoterapia Coletiva: críticas à Ergoterapia e ao hospício}

Ainda como efeito da Liberação (da ocupação nazista) na França, criou-se um coletivo de psiquiatras, originários de práticas e horizontes diversos (além dele, Ajuriaguerra, Bernard, Bonnafé, Daumézon, Duchêne, Ey, Follin, Fouquet, Lacan e Tosquelles), 
denominado Dr. Batia (um fictício Dr. Esperança, na língua basca), envolvendo poucas reuniões, vida breve, nenhuma publicação. Desde 1946, Henri Ey, porta-voz da Psiquiatria francesa de então, propositor nos anos 1930 de uma terceira via doutrinal, o "modelo organo-dinâmico", organizou as "Jornadas de Bonneval", estimulando a forte polêmica em curso. Em 1949, durante a Guerra Fria, intelectuais marxistas (em especial os psiquiatras), submetidos à despótica disciplina do PCF (ele próprio submetido a decisões da URSS), assinam um abaixo-assinado contra a Psicanálise (crescentemente forte na França desde os anos 1920), como pseudociência burguesa. Neste contexto divisionista, em setembro de 1951 Ey organizou em Bonneval o Simpósio sobre a Psicoterapia Coletiva (BILLIARD, 2001) no qual se defrontaram as experiências inovadoras de Tosquelles (Saint-Alban), Sivadon (Ville-Évrard) e Le Guillant (Villejuif). Apesar da riqueza e da importância dos dois primeiros, este artigo se propõe a focar as colocações do terceiro.

No simpósio, Le Guillant criticou o hospital psiquiátrico enquanto instituição de uma maneira geral e, em particular, a Ergoterapia ali praticada. Quanto ao hospital, diz que a idéia de que ele possa ser terapêutico é um mito, visto que ele isola o paciente daquilo que poderia ter um real valor terapêutico, que são os grupos naturais aos quais o paciente pertence.

Deste modo, mais do que "tratar do hospital", como ao seu ver se propunha a Psicoterapia Institucional apresentada por Tosquelles (Saint-Alban), Le Guillant já preconizava tratar o paciente fora do hospital. Considerava que as alterações psicopatológicas eram a manifestação, no indivíduo, de conflitos que exprimiam as contradições sociais. Em função dessa concepção sociogênica da doença mental, propôs naquele momento uma "clínica nova" que privilegiasse, através de uma compreensão dialética da história do indivíduo, os eventos biográficos, as experiências concretas (BILLIARD, 2001, p.126), ou seja, o tratamento passaria por considerar a história da pessoa em seu grupo social. Nesta perspectiva, as relações entre saúde-doença mental e trabalho só poderiam ser compreendidas a partir da história de vida em contextos específicos de trabalho (o que a Ergonomia da Atividade posteriormente vai denominar trabalho situado ${ }^{3}$ ).

Le Guillant criticou também duramente as técnicas de grupo de então, considerando que elas flutuavam entre conceitos psicanalíticos imprecisos e uma Sociologia "aproximativa". Ele entendia que os hábitos de submissão estão bastante ancorados entre os homens, daí que o clima de um asilo não Ihe parecia propício à sua abolição.

Em sua intervenção no Simpósio, recusava qualquer analogia entre o hospital psiquiátrico e uma cidade ou uma fábrica, não havendo a seu ver por que caricaturá-las. Ou seja, em sua argumentação, o paciente deve participar de grupos, "mas de grupos humanos reais, 
aos quais ele pertence e continua a pertencer: sua família e seus amigos, sua cidade e seu país, seu sindicato e seu partido. É lá que se joga e se jogará sempre seu destino" (LE GUILLANT apud BI LLI ARD, 2001, p. 103).

Quanto ao trabalho dos pacientes, à diferença de Sivadon, Le Guilllant afirma que a Ergoterapia só seria eficaz se se apoiasse no trabalho tal qual ele existe na sociedade real e que, dessa forma, deveria ser remunerado (considerado o regime de salariato já presente naquela sociedade). Assim, Le Guillant propôs que só seria possível uma Ergoterapia - isto é, que esta só teria valor de reeducação e readaptação - se ela buscasse aproximar o paciente do trabalho efetivamente considerado na sociedade existente, o trabalho remunerado, cabendo à equipe de cuidados apoiar a busca daquele tipo de trabalho, entendendo que "o ponto essencial consistia em garantir a regularidade do emprego e adaptá-lo às possibilidades da maior parte dos sujeitos, cuja diferença de nível é relativa à cada caso" (DALLE, DUBOIS, LE GUILLANT, HORASSIUS, RETANA, COX, LEFRANC, 2006).

Estas proposições vão ao encontro da idéia de "Empresa Social" (ROTELLI, 2000), criada pela Psiquiatria Democrática italiana, que busca não produzir dentro de uma estrutura fechada do hospício, mas em sociedade, em lugares abertos, o que a partir de 1987 foi tomada pela Comunidade Econômica Européia como paradigmática para projetos de reabilitação de grupos sociais frágeis (BARROS, 1994, p.102).

Le Guillant não recuou, em seu tempo, frente a questões da maior importância para os pacientes. Ainda hoje pergunta-se, por exemplo, se estas pessoas podem trabalhar como outras quaisquer e se tal trabalho deve ser remunerado; se esta reabilitação deve ocorrer no mercado, com todos os problemas que o capitalismo coloca (de exploração-dominação); caso se considere que o trabalho deve ser tomado como valor terapêutico, ou sua remuneração não teria a importância que teria para outra pessoa, ou se, ao contrário, a própria remuneração teria um valor fundamental; qual seria a capacidade de reabilitação que o trabalho poderia exercer para pessoas que estão vivendo em circuitos de psiquiatrização por longa data. Assim, pensar em limites e possibilidades da experiênciatrabalho para pessoas com transtornos mentais graves, traz uma série de questões que Le Guillant já enfrentou em seu tempo e que permanecem ainda sem resposta.

\section{A ideologia na Europa do Pós-Guerra}

Diversos fatores limitaram os avanços de Le Guillant nessas questões. Na Europa se instalava no imediato pós-guerra um modelo de desenvolvimento hegemonizado pelos EUA e dirigido pelo Plano Marshall, o que colocava os intelectuais ligados aos partidos ditos 
comunistas, ligados à URSS, em posição de grande pressão. A influência econômica dos EUA em uma Europa parcialmente destruída pela 2a Guerra trazia consigo uma visão a-histórica da sociedade, em que disciplinas como a Sociologia, a Psicologia e a Psiquiatria foram sendo dirigidas para uma função de vencer resistências aos modelos de produção exportados pelos norte-americanos e de adaptar os trabalhadores às mudanças técnicas e organizacionais. Sob os efeitos da "guerra fria" e a submissão dos Partidos ditos Comunistas à nascente URSS stalinizada, os psiquiatras ligados ao PCF acirraram a disputa no seio profissional, afirmando uma concepção que defendia as teorias de Pavlov como a verdadeira Psicologia (Vigotski excluído) e que explorava suas aplicações no campo social (BILLIARD, 1996). Também a Psicanálise passou a ser por este grupo recusada como possibilidade de compreensão dos fenômenos humanos, à medida que considerada pelos dirigentes internacionais da ideologia "socialista", e naquele momento por eles aceita, como uma "ciência burguesa", conforme posição que ficou ainda mais firme e claramente marcada após a saída do PCF do governo em 1947. Desde 1948, sob influência da patrulha ideológica stalinista ("comunista") aos intelectuais, chamada "jdanovismo", desenvolveuse um movimento de condenação da Psicanálise, levando Le Guillant, em 1949, junto com Bonnafé, Follin, Lebovici, a assinar um texto que lamentavelmente tornou-se histórico - La psychanalyse, idéologie réactionnaire - publicado em Nouvelle Critique (GAVELLE, 2003). Nele condenam (conforme decisão do PCF, seguindo ordens internacionais de ação na nascente "guerra fria") a Psicanálise como ideologia reacionária a serviço do que denominaram imperialismo americano e ciência burguesa. Alguns em seguida abandonaram o Partido, como Lebovici (o que não o impediu, como presidente da IPA, de ter ação reacionária frente aos eventos ligados à Psicanálise no Brasil, durante a ditadura militar). Não é o caso de Le Guillant, que ainda se manteve no PCF até a segunda metade da década de 1960.

Em 1947 Le Guillant assinou com outros intelectuais do Partido um texto contra o freudismo, considerando que este psicologizaria o social em favor de uma "[...] ordem burguesa das coisas" (DORAY, 1996, p.134). Foi neste ambiente de cega disputa ideológica, que em 1951 Le Guillant fundou, junto com Wallon, Bonnafé, Follin, Laffite e outros, a revista La Raison. Cahiers de Psychopathologie Scientifique (A Razão. Cadernos de Psicopatologia Científica), mantendo-se como redator-chefe até 1956. Esta revista, inicialmente inspirada nos princípios pavlovianos, procurava publicar artigos que estudavam os problemas de saúde articulando-os às condições de ligação entre o organismo e o que denominavam meio (BILLIARD, 2001). 


\section{Novas investigações sobre os processos de saúde / doença mental e trabalho}

Desde os anos 1930 se desenvolvia na França um movimento psiquiátrico reformista, rumando para uma subversão de todo o aparelho de cuidados - acolhimento, ressocialização e tratamento a ser realizado o mais próximo possível do lugar de vida do indivíduo. O futuro se revelou, na França, na proposta e encaminhamento da Psiquiatria de Setor.

Quanto a Le Guillant, cada vez mais se dirigiu aos mundos do trabalho, para situações que aconteciam fora de instituições psiquiátricas, em um percurso em parte possibilitado por um movimento realizado pela Psiquiatria Social.

De fato, a Psiquiatria Social do fim da década de 1940 na França passou a realizar uma reflexão sobre o próprio lugar da Psiquiatria na sociedade. Desta maneira, não mais se restringiu a um movimento de transformação dos hospitais psiquiátricos e à criação de estruturas extra-hospitalares para tratar de doentes mentais. Ela foi em direção à sociedade, preocupada em criar um ambiente de maior aceitação daqueles que entendiam como doente mental e em prevenir futuros problemas desta ordem. Este movimento de psiquiatras voltou-se para os grupos reais e para os mundos do trabalho real, aproximando-se de outras categorias profissionais como enfermeiros e, em especial, aos médicos do trabalho (op. cit., p.139). Com isto, psiquiatras como Le Guillant, Bonnafé, Sivadon e Veil buscaram conhecer, para denunciar e intervir, as condições de vida individuais e coletivas, supostamente capazes de provocar ou agravar problemas mentais.

Quanto a Le Guillant, como psiquiatra de esquerda, ligado ao PCF durante parte de sua vida profissional, mantinha proximidade com alguns sindicatos (CGT), o que o levou a aumentar seu interesse pelas condições de trabalho de algumas profissões e levantar problemas psicopatológicos que nelas se apresentavam (op. cit., p.269). Assim, aproximou três campos de saberes distintos: mundo/movimento dos trabalhadores, Medicina do Trabalho e Psiquiatria, realizando um "casamento pouco freqüente entre a consciência operária e a ciência dos doutores" (DORAY, 1996, p.126). Toda esta riquíssima movimentação evoluiu em direção a portarias e circulares ministeriais na França. Em 1952, a circular 148 normatizava a desaparição de tudo que estivesse lembrando o universo carcerário. Pretendendo assinalar a ruptura com o período asilar, os novos hospitais sob responsabilidade ministerial passaram a ser denominados "centros psicoterápicos", concebidos como unidades de cuidados de pequena dimensão, como um centro de intercâmbio social. Outra circular, de 1958, regulava as questões relativas ao trabalho e à remuneração dele conseqüente, através de uma circular que revertia a lógica asilar, já que nela até então 
pregava-se que o produto do trabalho dos doentes pertencia ao estabelecimento, como compensação pelos gastos públicos. A partir desta nova circular o produto do trabalho dos doentes passa a pertencer aos doentes, confirmando as regras geradas na experiência de Saint-Alban.

\section{Conclusão}

Procurou-se neste artigo uma aproximação a alguns dos feitos no campo da Reforma Psiquiátrica francesa deste psiquiatra e pesquisador apaixonado pela vida, esperando que sua obra (seus escritos e suas corajosas e férteis experimentações) possa ser mais bem conhecida no Brasil, entendendo que isto poderá lançar luz a alguns desafios enfrentados hoje no campo da atenção à saúde mental.

Os limites deste artigo permitem apenas uma aproximação, de modo que nele estão contidas diversas possibilidades posteriores de investigação sobre o que se pode realizar hoje em termos de trabalho, moradia, organização de usuários e profissionais dos serviços de saúde mental.

Le Guillant ajuda a lembrar que o humano deve sempre ter a oportunidade de buscar produzir condições de vida segundo suas próprias normas, já que cabe a ele lutar e escapar ao que o preconceito social colocaria como sendo seu desígnio (ATHAYDE, 1996). Neste sentido, a herança de Le Guillant pode oferecer ferramentas para os avanços da Reforma Psiquiátrica no Brasil. Infelizmente sua morte prematura em 1968 interrompeu um processo de produção rico e dinâmico.

Cabe, doravante, enfrentar os desafios frente aos quais Le Guillant não recuou, e avançar frente aos problemas que hoje permanecem.

\section{Referências Bibliográficas}

AMARANTE, P. Uma Aventura no manicômio: a trajetória de Franco Basaglia. História, Ciências, Saúde - Manguinhos, Rio de Janeiro, V. I, n.1, p. 61-77, jul.- out., 1994.

ATHAYDE, M. Coletivos de trabalho e modernização, 1996, 230 p. Tese (Doutorado em Engenharia de Produção), Coordenação de Programas de Pós-Graduação em Engenharia (COPPE), Universidade Federal do Rio de Janeiro (UFRJ), Rio de Janeiro.

BARROS, D. Jardins de Abel: Desconstrução do Manicômio de Trieste. São Paulo: Lemos / Edusp, 1994.

BASAGLIA, F. As instituições da violência. In: _-_. Escritos selecionados em saúde mental e reforma psiquiátrica. Rio de Janeiro: Garamond, 2005a. p. 91-132. 
BASAGLIA, F. A utopia da realidade. In: Escritos selecionados em saúde mental e reforma psiquiátrica. Rio de Janeiro: Garamond, 2005b. p. 225-236

BILLIARD, I. Les conditions historiques et sociales d'apparition de la Psychopathologie du Travail en France (1920 - 1950). In: CLOT, Y. (Org.), Les Histoires de la Psychologie du Travail: Approche Pluri-disciplinaire. Toulouse: Octarès, 1996. p.69-84.

Santé mentale et travail: L'Émergence de la Psychopathologie du Travail. Paris: La Dispute/SNEDIT, 2001.

BRASIL, 2000. Portaria $\mathbf{n}^{\circ} \mathbf{1 0 6 /}$ MS, publicada no Diário Oficial da União em 11 de fevereiro de 2000, Brasília.

CASTEL, R. (1978). A Instituição Psiquiátrica em Questão. In: FIGUEIRA, S. A. (Coord.). Sociedade e Doença Mental. Rio de Janeiro: Campus, 1978. p. 149-193.

CENTRE HOSPITALIER CHARCOT. Biographie du Dr. Louis Le Guillant. Mis à jour le 24/06/2008. Disponível em: http://www.chcharcot56. fr/histoire/biograph/guillant. htm Acesso em 26/07/2009.

CLOT, Y. (Dir.). Les histoires de la psychologie du travail. Approche pluri-disciplinaire. Toulouse: Octarès, 1996.

CODO, Wanderley, SAMPAIO, José Jackson Coelho, HITOMI, Alberto Haruyoshi. Indivíduo, Trabalho e Sofrimento: uma abordagem interdisciplinar. Petrópolis-RJ : Vozes, 1993.

CODO, W. Posfácio - O resgate de uma dívida. In : LIMA, E. A. (Org.). Escritos de Louis Le Guillant: da ergoterapia à psicopatologia do trabalho. Petrópolis: Vozes, 2006. p. 349-353.

DALLE, B. ; DUBOIS, R. ; LE GUILLANT, L. ; HORASSIUS, M. ; RETANA, COX, L. Uma experiência com 'oficinas terapêuticas'. . In : LIMA, E. A. (Org.). Escritos de Louis Le Guillant: da ergoterapia à psicopatologia do trabalho. Petrópolis: Vozes, 2006. p. 154172.

DARSES, Françoise, FALZON, Pierre, MUNDUTEGUY, Christophe. Paradigmas e modelos para a análise cognitiva das atividades finalizadas. In: FALZON, Pierre (Editor). Ergonomia. São Paulo: Editora Blucher, 2007. p.155-173.

DEJ OURS, C. Travail: usure mentale. Essai de psychopathologie du travail. Paris: Le Centurion, 1980.

DESVIAT, M. A Reforma Psiquiátrica. Rio de Janeiro: Fiocruz, 1999.

DORAY, B. Un regard sur l'oeuvre de Louis Le Guillant dans le domaine de la Psychopathologie du Travail. In: CLOT, Y. (Dir.), Les Histoires de la Psychologie du Travail: Approche Pluridisciplinaire. Toulouse: Octarès, 1996, p. 125-138.

FOUCAULT, M. História da loucura na idade clássica. São Paulo: Perspectiva, 1987. 
GALLIO, G. ; CONSTANTINO, M. François Tosquelles: a Escola de Liberdade. In: LANCETTI, A. (Org.), Saúde Loucura: Grupos e coletivos, $n^{\circ} 4$. São Paulo: Hucitec, 1994. p. 85-128.

GAVELLE, L. Mémoires: Lucien Bonnafé un psychiatre à l'assaut des bastilles. VST, Toulouse, n. 80, p. 51-52, 2003.

GOFFMAN, E. Manicômios, prisões e conventos. 7ạ ed. São Paulo: Perspectiva, 2001.

HESS, R. ; SAVOIE, A. (1993). Analyse Institutionel. Paris : PUF, 1993.

HOBSBAWM, E. Era dos Extremos: o breve século XX, 1914-1991.

São Paulo: Companhia das Letras, 1995.

J ACQUES, Maria da Graça Corrêa. Abordagens teórico-metodológicas em saúde/doença mental ; trabalho. Psicol. Soc. [online]., v.15, n.1, p. 97-116, $2003 . \quad$ Disponível em http://www.scielo.br/pdf/psoc/v15n1/v15n1a06.pdf. Acesso em 15/05/2009.

LE GUILLANT, L. Uma experiência de readaptação social. In : LIMA, E. A. (Org.). Escritos de Louis Le Guillant: da ergoterapia à psicopatologia do trabalho. Petrópolis: Vozes, 2006a. p. 154-172.

LE GUILLANT, L. Introdução a uma psicopatologia social. In : LIMA, E. A. (Org.). Escritos de Louis Le Guillant: da ergoterapia à psicopatologia do trabalho. Petrópolis: Vozes, 2006b. p. 23-74.

LE GUILLANT, L. ; BONAFFÉ, L. ; MIGNOT, H. Problemas suscitados pela cronicidade no plano das instituições psiquiátricas: estudo de 100 psicoses crônicas depois de 10 anos de tratamento. In : LIMA, E. A. (Org.). Escritos de Louis Le Guillant: da ergoterapia à psicopatologia do trabalho. Petrópolis: Vozes, 2006. p. 112-148.

LE GUILLANT, L., ACHAINTRE, JACQUELIN. A Organização do trabalho dos pacientes em um hospital psiquiátrico. In : LIMA, E. A. (Org.). Escritos de Louis Le Guillant: da ergoterapia à psicopatologia do trabalho. Petrópolis: Vozes, 2006. p. 149-153 LE GUILLANT, PARIENTE, ROELENS, TORRUBIA. Observações sobre um grupo de cem pacientes de um serviço fechado de um departamento de Paris. In : LIMA, E. A. (Org.). Escritos de Louis Le Guillant: da ergoterapia à psicopatologia do trabalho. Petrópolis: Vozes, 2006. p. 94-111.

GROUPE DE RECHERCHE LOUIS LE GUILLANT (Org.). Quelle Psychiatrie pour notre temps? Travaux et écrits de Louis Le Guillant. Toulouse: Erès, 1984.

LEVY-LEBOYER, C.; ESPERANDIO, J. C. La psychologie du travail en France, naissance et développement. In : C. LEVY-LEBOYER; J. C. ESPERANDIO (Orgs.) Traité de Psychologie du travail. Paris: PUF: 1987, p. 9-18.

LHUI LIER, D. Cliniques du travail. Toulouse: Éditions érès, 2006.

LIMA, E. A. A Psicopatologia do Trabalho - Origens e desenvolvimentos recentes na França. Psicologia, Ciência e 
Profissão, Brasília, a. 18, n. 2, p. 10-15, 1998. Disponível em http://pepsic.bvs-psi.org.br/pdf/pcp/v18n2/03.pdf Acesso em 23/04/2009.

LIMA, E. A. Esboço de uma crítica à especulação no campo da saúde mental e trabalho. In: JACQUES, M. G. ; CODO, W. (Orgs.), Saúde mental ; trabalho. Petrópolis: Vozes, 2002. p. 50-81.

LIMA, E. A. A polêmica em torno do nexo causal entre distúrbio mental e trabalho. Psicologia em Revista, Belo Horizonte, v. 10, n. 14, p. 82-91, 2003.

LIMA, E. A. (Org.). Escritos de Louis Le Guillant: da ergoterapia à psicopatologia do trabalho. Petrópolis: Vozes, 2006.

LIMA, E. A. Apresentação. In: LIMA, E. A. (Org.). Escritos de Louis Le Guillant: da ergoterapia à psicopatologia do trabalho. Petrópolis: Vozes, 2006. p. 7-11.

LOURAU, R. Análise I nstitucional. Petrópolis: Vozes, 1975.

MERLO, Álvaro Roberto Crespo. Psicodinâmica do trabalho. In : JACQUES, Maria da Graça, CODO, Wanderley Orgs. Saúde Mental ; Trabalho: leituras. Petrópolis, RJ, Vozes, 2002. p. 130-142.

NASSIF, L.F.A. Origens e desenvolvimento da Psicopatologia do Trabalho na França (século XX): uma abordagem histórica. Memorandum, Belo Horizonte, n. 8, p. 79-87, 2005. Disponível em http://www. faich.ufmg. br/ memorandum/artigo08/nassif01.htm Acesso em 22/06/2009.

ORSTMAN, Oscar. Mudar o trabalho: As experiências, os Métodos, as Condições de Experimentação Social. Lisboa: Fundação Calouste Gulbekian, 1984.

PICANÇO, Paulo E. G. Violência no contexto da assistência psiquiatrica no Estado do Ceará. Disponível em http://www.hospitaldepsiquiatria.com.br/menu_03/artigos/art_002.h tm. Acesso em 23/07/2009.

ROTELLI, F. Empresa Social: Construindo Sujeitos e Direitos. In: AMARANTE, P. (Org.). Ensaios: Subjetividade, Saúde Mental, Sociedade. Rio de Janeiro: Fiocruz, 2000. p. 301-306.

SCHWARTZ, Y. Ergonomie, philosophie et exterritorialité. In: Le paradigme ergologique ou un métier de Philosophe. Toulouse: Octarès, 2000. p. 71-106.

SELIGMANN-SILVA, Edith. Crise econômica, trabalho e saúde mental. In: ANGERAMI, Valdemar Augusto (Org.). Crise, Trabalho e Saúde Mental. São Paulo; Traço, 1986. p.54-132.

VERTZMAN, J.; CAVALCANTI, M. T.; SERPA JÚNIOR, O. Psicoterapia Institucional: uma Revisão. In: BEZERRA JÚNIOR, B. e AMARANTE, P. (Orgs.). Psiquiatria sem Hospício: Contribuições ao Estudo da Reforma Psiquiátrica. Rio de Janeiro: Relume-Dumará, 1992. p. 17-30.

ZAMBRONI-DE-SOUZA, P. C. O trabalho como possível : o caso das pessoas com "transtornos mentais graves". 2006. 232 P. 
Tese (Doutorado em Psicologia Social) - Instituto de Psicologia, Universidade do Estado do Rio de Janeiro, Rio de Janeiro.

ZAMBRONI-DE-SOUZA, P.C. ; ATHAYDE, M. A contribuição da abordagem clínica de Louis Le Guillant para o desenvolvimento da Psicologia do Trabalho. Estudos e Pesquisas em Psicologia, UERJ, Rio de Janeiro, v. 6, n. 1. p. 6-19, 2006. Disponível em http://pepsic.bvs-psi.org. br/pdf/epp/v6n1/v6n1a02.pdf. Acesso em $\underline{02 / 02 / 2007 .}$

\section{Endereço par correspondência}

Paulo César Zambroni-de-Souza

Departamento de Psicologia UFPB/CCHLA/Campus I, Cidade Universitária, Conjunto Castelo Branco, CEP 58.059-900, João Pessoa - PB, Brasil

Endereço eletrônico : paulozamsouza@yahoo.com.br

Milton Athayde

Rua São Francisco Xavier, 524/10 andar, sala 10.009, bloco F, Maracanã, CEP 20550-900, Rio de J aneiro - RJ, Brasil

Endereço eletrônico : athayde.milton@gmail.com

Anísio José da Silva Araújo

Departamento de Psicologia UFPB/CCHLA/Campus I, Cidade Universitária, Conjunto Castelo Branco, CEP 58.059-900, J oão Pessoa - PB, Brasil

Endereço eletrônico : anisiojsa@uol.com.br

Ana Maria Ramos Zambroni de Souza

FIOCRUZ, Rua Leopoldo Bulhões, 1480, Manguinhos, CEP 21041-210, Rio de Janeiro - RJ, Brasil

Endereço eletrônico : anazamramos@yahoo.com.br

Recebido em: 30/07/2009

Aceito para publicação em: 19/10/2009

Acompanhamento do processo editorial: Deise Mancebo

\footnotetext{
Notas

* Doutor em Psicologia Social/UERJ

** Doutor em Engenharia de Produção/COPPE/UFRJ

*** Doutor em Ciências/FIOCRUZ

**** Bolsista do CNPq,Especialista em Saúde da Mulher na Modalidade de Residência - IFF / FIOCRUZ.

${ }^{1}$ Esta expressão (assim como esta argumentação) é utilizada por Bonnafé por ocasião das "Jornadas psiquiátricas" de 1945.

2 No século XIX, Philippe Pinel, juntamente com Esquirol, conseguem que Luis Felipe assinasse a Lei de 1838, que disciplinava a admissão dos doentes em estabelecimentos públicos e privados, além de garantir a proteção dos seus bens. Esta lei, que originou os asilos, opunha-se à segregação dos alienados, indicando, para tanto, a substituição de celas por dormitórios e a criação de locais para reuniões e descontração, conforme Pelicier (apud PICANÇO, 2009).

3 A ergonomia da atividade tem como objeto a atividade de trabalho, o que pressupõe abordar o trabalho em seu sítio, ou seja, em um contexto determinado e "em circunstâncias materiais e sociais particulares", conforme Darses, Falzon e Munduteguy (2007, p. 160).
} 